\title{
CONTROL, MONITOR AND ALARM SYSTEM FOR CLINICAL APPLICATION OF A MEMBRANE OXYGENATOR
}

\author{
J. Duffin, ${ }^{1}$ B. MARTin, ${ }^{2}$ ANd J.D. CoOper ${ }^{2}$
}

\section{INTRODUCTION}

THE DEvelopMent of commercially produced membrane oxygenators has led to clinical trials of these devices for long-term (days) respiratory support, in patients with potentially reversible respiratory failure.

When cardiopulmonary bypass is utilized for a relatively short time, for openheart surgery, it is reasonable to expect the pump technician to carefully observe and control the circuit, giving constant attention to the details of perfusion. Such constant vigilance is obviously impossible when conducting long-term extracorporeal membrane oxygenator support for respiratory failure.

If such long-term use is to become practical, the oxygenator support system must be highly reliable and simple to operate. Control of the pump should be automatic and various functions of the circuit should be monitored to indicate any system failure.

We have been conducting animal and human perfusions with such a membrane oxygenator system, developed by extending that described by Kolobow, ${ }_{1}^{1}$ and have found it to be highly satisfactory. The system can accommodate any of the commercially available membrane oxygenators which have a blood phase flow resistance that is low enough to allow perfusion by a single pump. It is the purpose of this report to present the details of the system.

Figure 1 shows the complete system housed on a mobile cart, while Figure 2 depicts the system in schematic form. The blood and gas circuits are described in the next two sections, followed by explanations of the system controls, monitors and alarms.

\section{Blood Circuit}

Venous drainage is through a special non-kinking, wire reinforced, segmented polyurethane catheter. ${ }^{* 2}$ This is attached to an eight-foot-long silicone rubber drainage tube (1/2-inch I.D. $\times 3_{4}^{\prime}$-inch O.D., Dow Corning Silastic), which connects to the lower left of the cart where it is held in place by an adjustable clamp. The drainage tube is wrapped with spiral cable wrap (Panduit) for protection against kinking and damage, and with insulation to prevent heat loss. Incoming blood

\footnotetext{
${ }^{1}$ Departments of Anaesthesia and Physiology, Institute of Bio-Medical Engineering, University of Toronto, Toronto, Ontario, Canada.

'Division of Thoracic Surgery, Toronto General Hospital, Toronto, Ontario, Canada.

Address reprint requests to: Dr. J. Duffin, Department of Physiology, Room 3321, Medical sciences Building, University of Toronto, Toronto, Canada M5S 1A8
}

-Made by Mr. Raymond Johnson, 15 Princeton Street, Peabody, Massachusetts. 


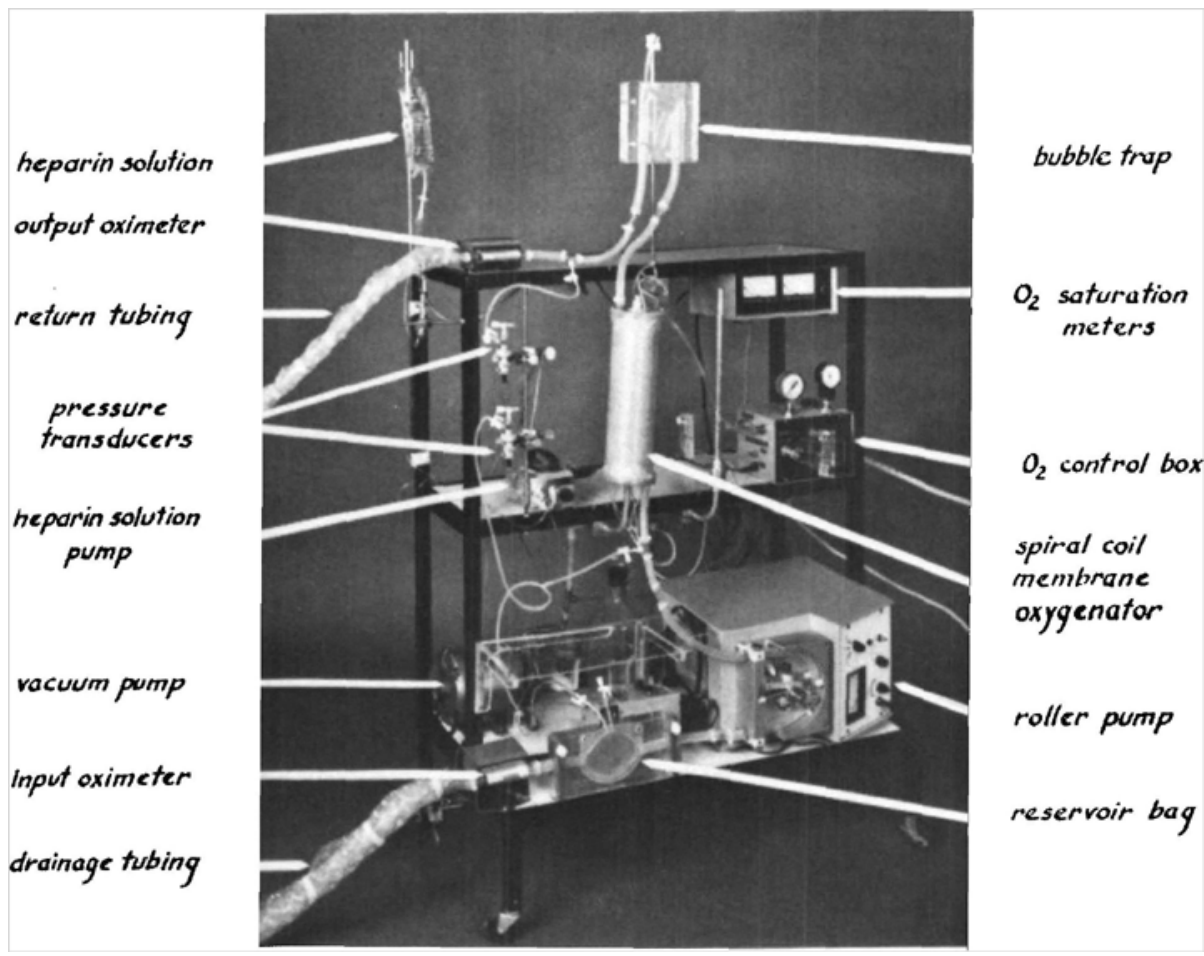

Figure 1. The membrane oxygenator system.

passes through a Lexan polycarbonate cuvette where oxygen saturation is determined, and then into a reservoir bag. $t$ The silicone rubber reservoir bag is confined by a hinged sandwich-type of holder which positions the lever arms of the flow alarm and pump speed control switches so that they register the bag's expan-

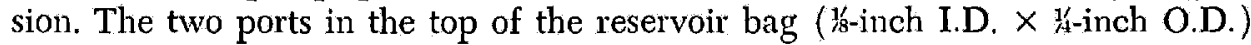
are used for fluid addition and the continuous infusion of heparin solution by a controlled flow pump (Holter, model 907).

From the reservoir bag, blood passes into a roller pump chamber made of silicone rubber tubing (1/2-inch I.D. $\times 11 / 16^{1}$-inch O.D., Dow Corning Silastic). All connectors between different sections of tubing are polycarbonate (Cobe Laboratories) and the tubing is securely fastened to the connectors with cable ties (Panduit). The roller pump (Sarns, model 6002) is adjusted so as to just occlude the pump chamber tubing.

After the pump, a length of silicone rubber tubing ( $\%$-inch I.D. $\times \%$-inch O.D., Dow Corning Silastic) conducts the blood to a spiral membrane lung (Sci Med Inc.) designed by Kolobow. ${ }^{1,3} \mathrm{~A}$ connector with a side port (Cobe Laboratories) is inserted in the tubing between the pump and the lung for pressure monitoring. Silicone rubber tubing ( $/{ }^{\prime}$-inch I.D. $\times{ }_{1}^{\prime \prime}$-inch O.D., Dow Corning Silastic) leads from the side port through a three-way tap to both a pressure transducer and, by means of a Y-connector, to the high pressure sensor. This sensor consists of a small

†Sci. Med. Inc., Minneapolis, Minnesota. 


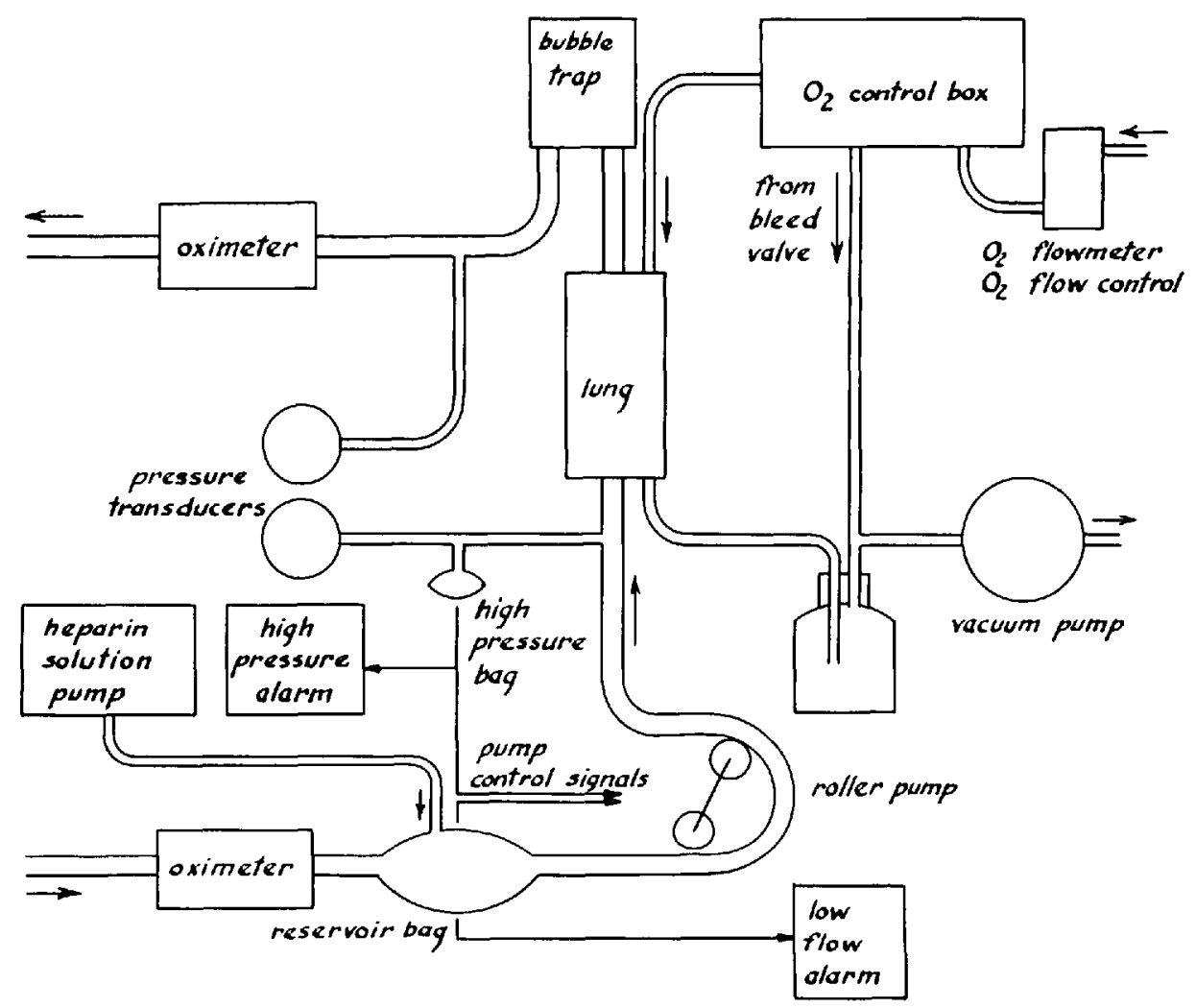

Figure 2. A schematic of the blood and gas circuits for the membrane oxygenator system.

silicone rubber bag, fabricated from two $1 \frac{1}{2}$-inch-square pieces of sheet rubber glued to each other around the edges. A length of $x_{s}$-inch I.D. silicone rubber tubing connects to the bag interior through a 1 -inch hole in the centre of one of the sheets (see Figure 5).

Upon leaving the membrane oxygenator, blood passes to a bubble trap (Sci Med Inc.). Optionally, a high-flow blood filter may be interposed between the membrane lung and the bubble trap for the initial few minutes of perfusion. The perfusion is then momentarily stopped and the filter discarded. From the bubble trap, blood is conducted to the output oximeter cuvette by silicone rubber tubing containing a connector with a side port for pressure monitoring. Blood leaves the system through an eight-foot-long return tube of silicone rubber $\left({ }^{\prime}{ }^{\prime}\right.$-inch I.D. $\times$ s:-inch O.D., Dow Corning Silastic) which is insulated and protected in the same way as the drainage tube.

\section{Gas Circuit}

The gas circuit is shown separately in Figure 3. It has been designed to allow the desired oxygen flow to pass through the gas phase of the membrane oxygenator at any desired pressure. This permits the gas phase pressure to be maintained 


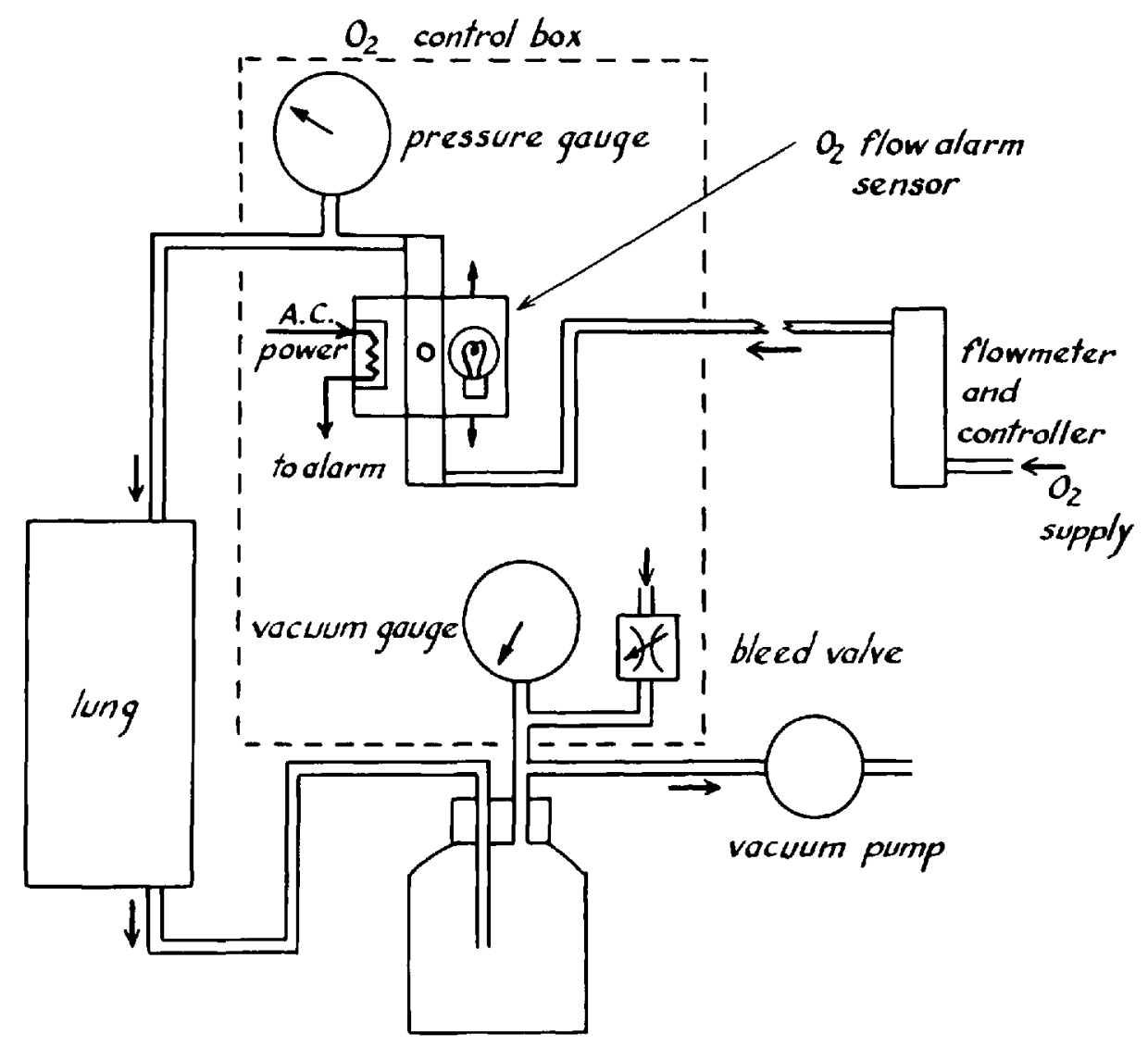

Figure 3. A schematic of the gas circuit for the membrane oxygenator system.

below the blood phase pressure as a safety precaution to prevent gas embolism should a leak develop in the membrane.

Cylinder or piped oxygen passes through a regulator flowmeter combination and, through tubing protected with spiral cablewrap (Panduit), connects to a control and alarm box. Within the control box, the oxygen flow is routed through a rotameter which forms part of the flow alarm, and leaves the box after a tee connection to a pressure gauge which displays the oxygen pressure at the inlet to the membrane lung. From the control box, the oxygen is fed to the upper gas port of the membrane lung. The gas port exit at the bottom of the oxygenator is connected by plastic tubing to a glass reservoir bottle through one hole of a twohole stopper. The bottle collects the water which condenses from the emerging gas and also serves to show blood leakage in the case of membrane damage.

The second hole of the reservoir bottle stopper is fitted with tubing which connects by a tee to a vacuum pump (Gast, model 0211, lubricated) and to an openended detachable connector (Imperial Eastman kwik-connect). The connector can either be left unconnected, allowing the gas to exit to room air or, if vacuum is to be used, it can be connected to the oxygen control box where it leads to a bleed valve, which controls the amount of vacuum exerted by the vacuum pump, 


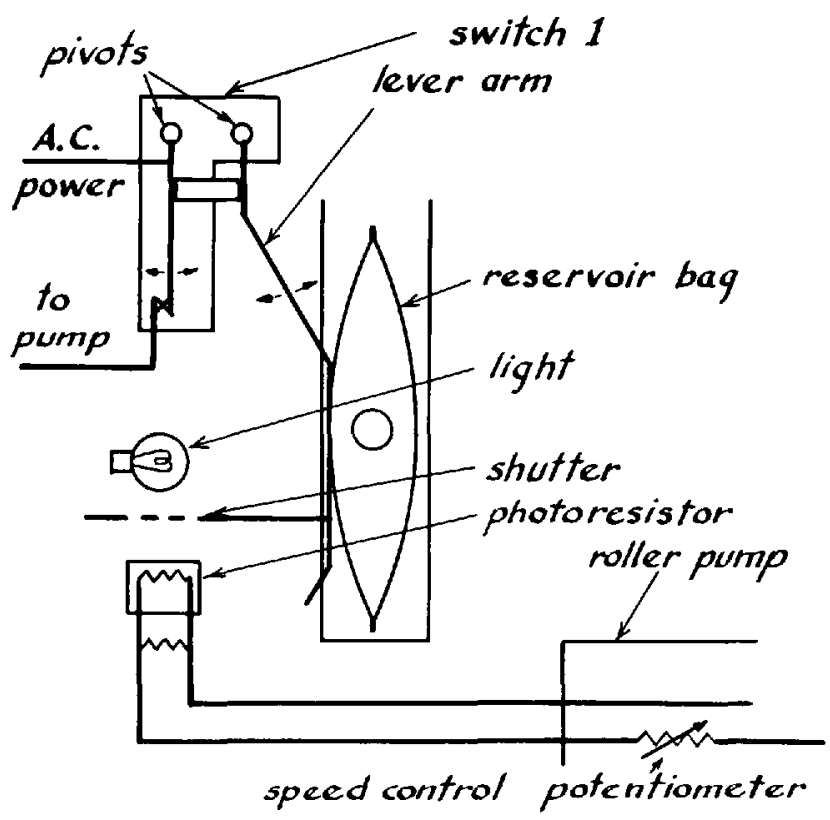

Figure 4. The operation of the pump servo control system in diagrammatic form.

and to a vacuum gauge. This gauge, mounted adjacent to the gas inlet pressure gauge, displays the amount of negative pressure applied to the outlet gas port of the oxygenator when the vacuum pump is in use.

\section{System Controls}

The most critical part of the oxygenator system is the roller pump. It must neither exhaust the reservoir bag and create suction nor produce too great an output pressure and cause blood circuit rupture, a circumstance likely to occur if the return line to the patient becomes kinked. Previous pump control schemes for this type of oxygenator have used on-off controls to prevent these conditions. ${ }^{4}$ We have extended such a control scheme to include a servo control of pump speed to match blood inflow. The control scheme described as follows derives its reliability from its simplicity.

Figure 4 shows the operation of switch 1 (Micro Switch type BE-2RV-A2) the lever arm of which monitors the reservoir bag volume. The lever arm has been modified by attaching a shutter which moves between a photoresistor (Clairex CL5M4L) and a light source $(6 \mathrm{w}, 120 \mathrm{v}$ bulb). The photoresistor and parallel $7.6 \mathrm{k} \Omega, 5$-watt resistor is connected in series with the pump speed control potentiometer by a phone plug and jack combination that restores normal pump control when withdrawn. The series combination of resistors operates such that the pump speed control potentiometer sets the maximum speed of the pump and the photoresistor matches pump speed to blood inflow up to the set maximum. In the event of servo control system failure, automatic control of pump speed is lost, but the 


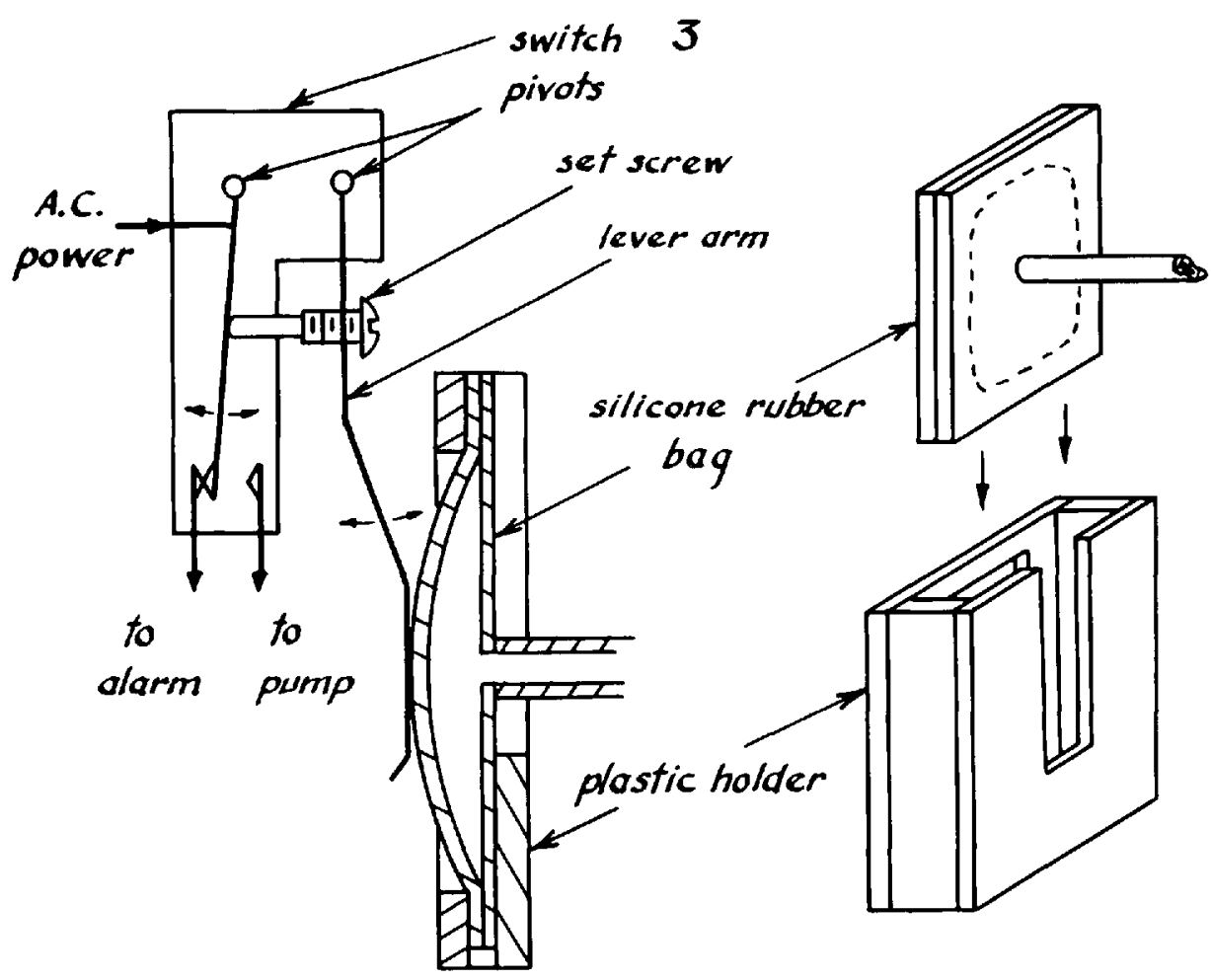
form.

Figure 5. The operation of the high pressure alarm and pump cut-off switch in diagrammatic

reservoir bag size is sensed by the lever of switch 1 , which deactivates the pump if the bag empties.

Switch 3 (Micro Switch BE-2RV-A2) operates as a high-pressure cut-off switch for the roller pump in conjunction with a small (1 1\%-inch square) bag made of silicone rubber. Figure 5 shows the bag and its holder on the right and a crosssectional view on the left. The bag is connected to the blood pressure monitoring port between the pump and the oxygenator. High pressure expands the bag and moves the lever of the switch which deactivates the roller pump. The lever arm of switch 3 has been modified by tapping a set screw over the operating plunger so that the pressure at which the cut-off switch deactivates the pump may be preset to any desired level. Both switches 1 and 3 are in series with the A.C. supply to the pump.

The control of gas pressure and flow through the membrane oxygenator must reconcile two dependent factors. The oxygen flow control sets the required gas flow through the oxygenator and thereby sets the gas pressure which occurs at the inlet port. However, the highest gas pressure in the membrane lung, that at the inlet, should be kept 25 to $100 \mathrm{~mm} \mathrm{Hg}$ below the lowest blood pressure within the oxygenator (blood exit port) so that good gas transfer is obtained and yet gas emboli are avoided in the event of a membrane leak. 
During veno-arterial perfusions the blood phase pressure is high and the chosen oxygen flow does not produce too high a pressure in the gas phase. During venovenous perfusions, however, the blood phase pressure is much lower and the gas inlet pressure due to the chosen flow may be too high. In this case, a vacuum pump is connected to the gas exhaust with a bleed valve connected in parallel so as to control the vacuum. The bleed valve is adjusted to alter the inlet gas pressure to that required.

\section{System Monitoring}

The performance of the system is monitored with meters that continuously display input and output blood oxygen saturation as determined by reflectance oximetry. ${ }^{\circ 5}$ The pump speed meter yields blood flow by a previously measured calibration chart, since the roller pump is used occlusively with standardized tubing.

In order to monitor the flow resistance of the blood phase of the membrane oxygenator, blood pressure before and after the oxygenator is measured with pressure transducers (Statham P23 Ia) connected to a pen recorder (HewlettPackard). The inlet pressure measurement also permits appropriate setting of the high pressure cut-off switch for the pump.

Oxygen flow is measured with a rotameter and the resulting pressure at the gas inlet to the oxygenator is monitored with a diaphragm pressure gauge. Reduction of the inlet pressure may be accomplished by applying a vacuum at the gas exit from the oxygenator, and this vacuum is monitored with another diaphragm pressure gauge.

In addition to the continuous monitoring described above, blood samples are taken from the system for blood gas analysis every four hours (patient every hour) and for coagulation time measurements every hour (Haemochron) $f$ after system stabilization.

\section{System Alarms}

Situations beyond the automatic control of the system and requiring intervention by clinical personnel are audibly alarmed using the following code:

1. Excessive pressure occurring in the blood circuit following the pump is a 2.9 $\mathrm{kHz}$ pulsating tone (Sonalert).

2. A decrease in blood inflow to the system is a steady $2.9 \mathrm{kHz}$ tone (Sonalert).

3. A change in the oxygen flow to the oxygenator is a $4.5 \mathrm{kHz}$ pulsating tone (Sonalert).

4. Failure of A.C. power to the cart is a ringing bell.

Switch 3 in Figure 5 is used both as a roller pump cut-off switch and a switch for the high pressure alarm.

Switch 2 (Micro Switch BE-2RV-A2) in Figure 6 is the alarm switch for a decrease in blood inflow to the system. Its lever arm senses reservoir bag volume

"Made by Mr. Robert Simpson, 90 Caines Ave., Willowdale, Ontario.

tInternational Technidyne Corp., Metchen, New Jersey. 


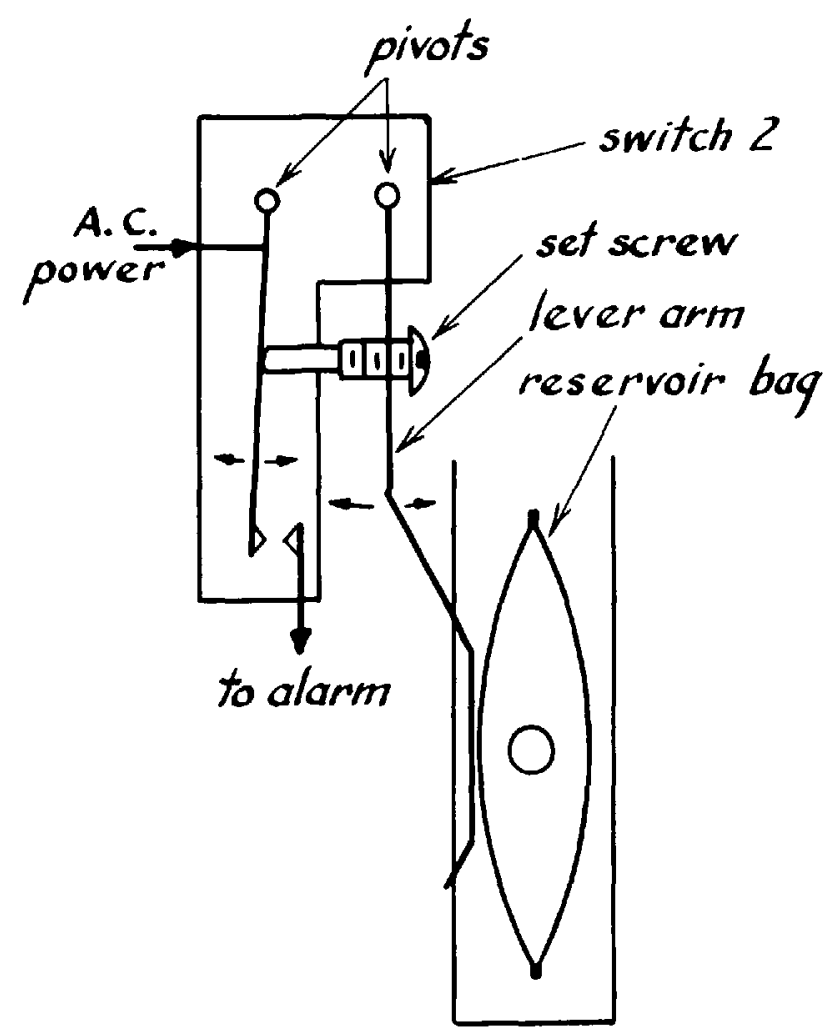

FigunE 6. The operation of the low-flow alarm switch in diagrammatic form.

and, since a decrease in blood inflow to the system results in a decrease in reservoir bag volume, switch 2 functions as a low blood inflow sensor. The lever arm of switch 2 has been modified by tapping a set-screw over the operating plunger so that the flow at which the switch activates the alarm may be preset at any desired level.

The oxygen flow alarm was contrived from a photoresistor-lamp combination which senses the presence of a rotameter bead and turns the alarm off. The rotameter is housed in the oxygen control box and is in series with the artificial lung. The photoresistor-lamp combination is moveable on the rotameter column so that any chosen flow may be alarmed.

The power failure alarm consists of a box containing a rechargeable battery, a bell-type alarm, a battery charging circuit, and a relay. Power to the cart energizes the relay and connects the battery to the charger. If power is interrupted, the de-energized relay connects the battery to the alarm bell.

\section{Conclusion}

A reliable and easily operated membrane oxygenator system has been developed and equipped with safeguards to reduce the chances of system failure during prolonged use. This system has operated without failure in four clinical cases of 
long-term respiratory support of $6 \frac{12}{12}$ days, 59 hours, 62 hours and 48 hours, ${ }^{6,7}$ as well as for a series of animal (sheep) perfusions totalling over 400 hours.

\section{SUMMARY}

Membrane oxygenators, now commercially available, are undergoing clinical trials as long-term (days) respiratory support devices for patients in potentially reversible respiratory failure. However, these devices must be used in an integrated system of controls, monitors and alarms if they are to be reliable and easy to operate in the clinical environment. This paper describes such a system.

The tubing circuits for blood and for oxygen are described first. Next, details of the blood pump controls are presented. The system features servo control of pump speed to match blood inflow, and deactivation of the pump in the case of excessive output pressure. Gas circuit controls are described which allow the independent adjustment of both oxygen flow through the gas phase of the membrane lung and oxygen pressure developed at the inlet gas port. Audible alarms are provided for low blood inflow to the system, excessive blood outflow pressure, changes in oxygen flow and failure of the electric power supply to the system. In addition to pressure and flow monitors in the blood and gas circuits, blood oxygen saturation is continuously monitored at both input and output of the system.

The membrane oxygenator system has proved to be reliable and easy to operate in both animal and human long-term perfusions.

\section{RÉsUMÉ}

Les oxygénateurs à membrane qui ont fait leur entrée sur le marché sont soumis actuellement à des essais cliniques comme moyen de support à long terme chez des patients en insuffisance respiratoire dans le cas où cette insuffisance est jugée possiblement réversible.

Il est cependant nécessaire d'intégrer à ces oxygénateurs des systèmes de moniteurs, de contrôles et d'alarmes afin de les rendre fiables et faciles d'opération en clinique. Les auteurs présentent leur version d'un tel système.

Ils décrivent d'abord le montage du circuit du perfusat, et celui de l'oxygène. Suit une description des contrôles de la pompe, qui comprend un ajustement automatique du débit en fonction du retour veineux et, un arrêt automatique en cas de pression excessive décelée du côté artériel du système.

De même, les circuits gazeux comportent des contrôles qui permettent l'adjustement indépendant du débit d'oxygène vers la phase gazeuse de l'oxygénateur ainsi que la pression de gaz à l'entrée de l'oxygénateur.

Des alarmes sonores avertissent en cas de bas retour veineux, de pression excessive du côté artériel du système, de changements dans le débit d'oxygène en finalement en cas de panne de courant. En plus du monitoring, du débit et de la pression survenant dans les circuits de liquides et de gaz, la saturation du sang en oxygène est mesurée de façon continue à l'entrée et à la sortie du système.

L'oxygénateur à membrane utilisé de cette façon s'est montré fiable et facile d'opération dans les perfusions prolongées chez l'animal et chez l'homme. 


\section{ACKNOWLEDGMENTS}

We wish to express our thanks to Dr. Warren M. Zapol and his staff at the Massachusetts General Hospital for their advice in the development of the system, and to Mr. R. Simpson and Mr. J. Nicholiades of the Institute of Biomedical Engineering for their technical assistance.

This work was supported by the Medical Research Council of Canada and The Ontario Heart Foundation.

\section{REFERENCES}

1. KoLoBow, T. \& ZAPOL, W. Partial and total extracorporeal respiratory gas exchange with the spiral membrane lung. In: Mechanical Devices for Cardiopulmonary Assistance. Eds. R.H. Bartlett, P. Drinker and P.M. Galletti. Basel, S. Karger (1971).

2. KoLOBOW, T. \& ZAPOL, W. A new thin-walled nonkinking catheter for peripheral vascular cannulation. Surgery 68: 625 (1970).

3. KоLовоw, T., ZAPOL, W., \& Marcus, J. Development of a disposable membrane lung for organ perfusion. In: Organ perfusion and preservation. Eds. J.C. Normal, J. Folkman, W.G. Hardison, L.F. Rudolf, and F.J. Veith. New York, Appleton-Century-Crofts (1968).

4. McCullovgh, N.J., Falke, W., Lowenstein, E., Buckley, M.J., Schmidt, V., \& Zapol, W.M. Respiratory gas exchange with spiral coil membrane lungs: total cardiopulmonary bypass in adult sheep and clicinal experience with long-term perfusion in adult patients. Mt. Sinai J. Med. 15: 207 (1973).

5. Vurex, G.G., Kolouow, T., \& Pegram, S. High-precision oxygen saturation monitor for extracorporeal circulation applications. Med. Instrum. 7: 262 (1973).

6. Cooper, J.D., Duffin, J., \& ZAPOL, W.M. Cannulation of ascending aorta for long-term membrane oxygenator support. J. of Thoracic and Cardiovascular Surg. 69: 905 (1975).

7. Cooper, J.D., Duffin, J., Glynn, M.F.X., Nelems, J.M., Teasdale, S., \& Scott, A.A. Combination of membrane oxygenator support and pulmonary lavage for acute respiratory failure. J. of Thoracic and Cardiovascular Surg. (In press). 